\title{
PALABRAS del Exmo. Sr. D. MANUEL FRAGA IRIBARNe, Presidente de la Xunta de Galicia, pronunciadas en el Acto Académico celebrado en el \\ Salón de Actos de la Facultad de Derecho de la Universidad de Sao Paulo (Brasil)
}

\author{
Sr. Rector de la Universidad de Sao Paulo, \\ Sr. Director de la Facultad de Derecho, \\ Señoras y Señores Claustrales, \\ Señoras y Señores:
}

Me honrais mucho al recibirme hoy en el seno del alma mater paulista. Me obsequiais, además, con el hermoso Diploma que me acabais de entregar. Y me abrumais, en fin, con una guirnalda de elogios que no creo merecer, pero que no puedo rechazar, por venir de quien viene, es decir, de la Facultad de Derecho de la Universidad de São Paulo. Todo es tan sobresaliente en esta instituición que el visitante no sabe qué admirar más aquí. ¿El edificio mismo y sus instalaciones para el estudio y la investición? ¿O bien la producción ciêntífica, de la que es buque insignia la impresionante colección de volúmenes publicados por la Revista da Faculdade de Direito da Universidade de São Paulo? ¿O quizá la galería de profesores honorarios, eméritos, catedráticos, titulares, adjuntos y libres docentes que ha tenido y tiene? ¿O, en fin, la increíble nómina de alumnos suyos que han ocupado u ocupan ahora mismo las máximas magistraturas jurídicas, políticas, económicas y sociales del imperio, antes, y ahora de la república?

\section{I}

Éstos son los sentimientos que ahora embargan mi ánimo y que motivan la alegría que experimento, en mi condición de catedrático de derecho, al aprovechar la ocasión que me dais de incorporarme en la compañia paulista a la sobresaliente legión de juristas que formam la jurisprudencia brasileña. La cual merece mucho más que el pobre elogio que yo, sin embargo, deseo dedicarle ahora.

Son parte de la gran jurisprudencia brasileña privatistas ilustres como el mercantilista José da Silva Lisboa, e exégeta António Joaquim Rivas, el pandectista Lafayate Rodrigues Pereira, y el historicista Teixeira de Freitas, entre los más clássicos; y Lacerda de Almeida, Eduardo Espínola, Inglez de Souza, y los dos Carvalho de Mendonça, en la siguiente generación; y tambiém, pasando a los mas 
recientes, Gondim Neto, Virgilio de Sá, San-Tiago Dantas o Waldemar Ferreira. Para todos esos maestros, mi fervoros homenaje.

No menos que los privatistas brillan los iuspublicistas en la misma tradición jurisprudencial. ¿Cómo no recordar y homenajear, de entre ellos, a João Barbalho, a Rui Barbosa, a Carlos Maximiliano, a Castro Nunes, o a Pimento Bueno? ¡Cuánto he aprendido de ellos, desde mis primeros años de professorado!

Y lo mismo se diga de los jurisprudentes generales, dedicados a la Teoría y a la Filosofía del Derecho. Me refiero a maestros famosos como Tristán de Athayde, Tobías Barreto, Silvio Romero, Queirós de Lima, Clóvis Bevilaqua, Rui Barbosa, Galvâo de Souza, Miguel Reale, Dourado de Gusmão, Cirell Czerna, Sampaio Ferraz etc. etc. Ellos son, probablemente, los juristas brasileños más leídos allende fronteras; y no sólo porque sus investigaciones han tenido eco y seguimiento mundial. Lo que ocurre, paradigmaticamente, en el caso de Miguel Reale, cuya teoría tridimensional del derecho ha sido el único dique cierto a la universal inundación kelseniana y la única doctrina jurídica que, con todas las matizaciones que se quiera, ha sido recibida y aceptada por toda la comunidad científica internacional y singularmente por la iberoamericana. ${ }^{1}$

\section{II}

Vistos desde el otro lado del Atlántico, el derecho y la jurisprudencia científica brasileña presentan un panorama sólido y esperanzador. No es que carezcan de defectos necesitados de subsanación, o de problemas pendientes de resolutión. Los juristas brasileños vienen denunciando durante los últimos decenios algunos defectos de su jurisprudencia y de su sistema jurídico dignos de ser corregidos. $^{2}$ Así, p.e., el exceso de libros didácticos demasiado superficiales, bastante acríticos, repetitivos, poco inovadores, ayunos de información nacional, dependientes de modas exteriores, e incluso colonizados mentalmente. También se

1. Cfr. Nelson Saldanha, "La filosofia del derecho en Brasil en su fase más reciente". Rivista Internazionale di Filosofia del diritto, 60(1983) 106 ss. Tercio Sampaio Ferraz, "La Philosophie du Droit au Brésil après la Deuxuème Guerre Mondiale: Le ròle de Miguel Reale". Archives de Philosophie du Droit, 34 (1989) 233 ss.

2. Cfr. Alfredo Morles Hernández, "La cultura jurídica brasileña y su contribución al desarrollo del derecho en la América Latina". Boletin de la Academia de Ciencias Politicas y Sociales de Caracas, 50-51 (1972) 237-264. Miguel Reale, 100 Anos de Ciencia do Direito no Brasil. São Paulo, Saraiva, 1973. Miguel Reale, "A Experiência Jurídica Brasileira”, Revista da Faculdade de Direito da Universidade de São Paulo, 49/2 (1974) 13-35. 
ha denunciado el exceso volumenes dedicados a reproducir normas y dicisiones, y a los que falta el imprescindible marco teórico, aunque se publican bajo la rúbrica de leyes comentadas. En defensa de la autoidentificación que tales prácticas ponen en peligro, ha llegado a escribir Reale ${ }^{3}$ que en muchos colegas "falta una crítica interna que determine el processo de las ideas en razón de nuestro propio proceso investigador, es decir, como resultante de un diálogo directo entre los juristas brasileños, y no como un reflejo mecánico debido a la recepción de doctrinas alienígenas opuestas"; y que "aunque hemos hecho notables progresos, aun persiste el vicio de pensar que sólo se hace ciencia cuando se citan autores extranjeros"; concluyendo que, a su entender, "ya es tiempo de superar esta alienacion jurídica"

También vienen denunciando la necessidad de que el derecho en particular la legislación y la jurisdición ayuden a resolver el agudo déficit de vigencia de los derechos humanos de contenido económico, social y cultural, que padece la república: ${ }^{4}$ problemas que no se pueden resolver sólo con actuaciones legislativas, judiciales o doctrinales, pero que tampoco se resolverán al margen o a redropelo de ellas. No es momento, sin embargo, de proseguir la reflexión por el análisis de estos aspectos concretos. Baste decir que confío en la capacidad de los jurisprudentes y jurisconsultos brasileños para reformar en su derecho todo lo que sea necesario, de manera que se atenuen o se eliminen limpiamente los problemas de justicia y convivencia que tiene esta gran nación o los defectos formales y materiales antes aludidos. La existencia de un diagnóstico crítico interno asegura, a mi entender, la eficacia de la terapéutica.

\section{III}

Pero antes y más allá de la inevitable lucha por el derecho que es toda jurisprudencia, según explicara Ihering, la brasileña posee ciertas notables características que son de mi especial agrado, y que constituyen, a mi modo de ver, como un conjunto de principios de su desenvolvimiento. Entre tales principios me

3. En su ensayo sobre "A Experiência Jurídica Brasileira", cit., p. 19.

4. Cfr. "Brazil: Myths and Realities on Human rights and Woman Wrongs", en Towards a Human rights Framework, New York, Praeguer, 1992, p. 71-85. 
permito destacar tres: el principio de autoidentificación, el principio de realismo concreto, $y$ el principio de reforma permanente.

El primero los principios que connotan positivamente a la ciencia jurídica brasileña es, en mi opinión, el principio de autoidentificación. En efecto, la ciencia jurídica brasileña posee la percepción de lo que bien se puede denominar el espíritu del derecho brasileño, o la conciencia de la propia identidad y de la propia diferencia. Y ello, sin rechazar lo que viene de afuera. Al contrario, acogiendo siempre con curiosidad las novedades incluídas en cualquier técnica o programa exterior, pero sabiendo reconducirlas a la síntesis con lo nativo para la mejor resolución de los problemas jurídicos más imprevistos o más escasos de precedentes propios. $^{5}$

La doctrina jurídica brasileña se fortalece, en segundo lugar, con el principio de realismo concreto. En su virtud, los juristas brasileños han guardado siempre una constante fidelidad a la realidad concreta y han aceptado solamente dosis mínimas -casi vacunas profilácticas- de los sistemas jurídicos más idealistas, racionalistas o estrafalarios, y por ello más peligrosos para la preservación de la propia identidad. De ahí se sigue la virtud del sentido común, del sentido práctico, y aún del sentido pragmático que resuelve casi siempre los conflictos con menos costos que cuando se les aplican sutilidades académicas. Es que las soluciones doctrinales prácticas son casi siempre más ricas en valores actualizables que las posiciones abstractas cuya rigidez se disimula con filigranas teoréticas, aún más embarazosas para quien las usa.

La jurisprudencia brasileña se connota, en fin con el principio de reforma permanente. Y por su gracia, la sociedad brasileña ha tenido la suerte de mantener unido un gran Estado, sin verlo romperse; así como la fortuna de haber ido adaptando a las respectivas situaciones todo su derecho -el normativo, el jurisdiccional y el jurisprudencial- comenzando por la propia constitución -mediante la técnica de la enmienda- sin tener que sufrir saltos bruscos ni revoluciones, rupturas o involuciones.

Esos sólidos fundamentos le dan tal vigor al Derecho y a la Jurisprudencia brasileña que no es preciso ser un vidente para augurarle días de

5. Cfr. Mario G. Losano, "La Scuola di Recife e I'influenza tedesca sul diritto brasiliano", Materiali per una sotria della cultura giuridica, 4 (1974) 321 ss. Tercio Sampaio Ferraz, "Deutsches Gedankengut in der brasilianischen Rechtsphilosophie", Archiv für Rechts- und Sozialphilosophie, 71 (1985) 1 ss. 
gloria. Tal premonición viene avalada por todos los indicadores culturales importantes, que ahí están acreditando la existencia de grandes facultades, como ésta; de eminentes profesores, como los que aquí enseñan e investigan; y de millares de alumnos, como los que aquí aprenden a diario. Todas esas cosas son una garantía. Y a ellas se añade una primordial, para la nueva época pluralista en que estamos entrando, que es la vivencia extraordinaria por parte de toda la sociedad brasileña -y de su clase jurídica antes que ninguna otra- del pluralismo, gracias al cual son posibles y tienen vigencia los principios antes enumerados.

\section{IV}

El pluralismo social y jurisprudencial brasileño es admirable. La jurisprudencia brasileña, no sólo es que acoge y critica todo lo que se innova mundo adelante. Es que tiene recursos propios en su propia tradición, para asimilarlo, sin desnaturalizar-se, partiendo de las inmensas posibilidades que se siguen del multicolor abanico de conceptos del derecho que ella misma ofrece. Y esto último le da al jurisconsulto brasileño una notable ventaja sobre sus competidores. A diferencia de lo que le ocurre a casi todos los demás, un jurista brasileño puede defender una causa normativa, judicial o doctrinal, según convenga, desde muy distintas ópticas fundamentales, sin necesidad de salir de sus propias pautas idiomáticas y culturales; o sea, apoyándose en su propia tradición y no viéndose necesitado a acudir a autoridades foráneas.

Así que el jurista fundamentarse en el derecho como un hecho espiritual, en el cual y por el cual se concr tan históricamente valores, al ordenarse normativamente relaciones intersubjetivas respecto de las exigencias complementarias de los individuos y la comunidad, no tiene más que mantenerse en el tridimensionalismo realiano patrio. Pero el que prefiere manejar el derecho como un juego aleatorio de relaciones meta-complementarias y jerárquicas establecidas entre una autoridad y un sujeto, no tiene más que acudir a Sampaio Ferraz.

¿Le interesa a un abogado razonar bajo el supuesto de que el derecho sea un instrumento capaz de traducir socialmente en bienes de vida y libertad las aspiraciones más altas del espiritu? Déjese orientar por Rui Barbosa. ¿Le conviene a otro, en cambio, pensar el derecho como norma ética inducida del estado de civilización del grupo social? Pues puede inspirarse en Clovis Bevilacqua. 
Quien precise razonar desde el derecho como complejo de las condiciones creadas por el espiritu de cada época, que sirven para hacer posible la coexistencia social mediante la limitación del conflicto entre las libertades, sólo tendrá que acudir a la autoridad de Silvio Romero. Mas quien necesite en una coyuntura argumental entender el derecho como un principio de selección en la lucha por la existencia, le bastará con acudir a Tobías Barreto. ${ }^{6} \mathrm{Y}$ así, indefinidamente.

\section{V}

Debo concluir y quiero hacerlo afirmando que somos muchos los que creemos en El gran Brasil, denominación que ya utilicé en 1958 para titular un estudio sobre las Constituciones Políticas de este país, que procuré documentar debidamente con dos viajes, uno efectuado ese mismo año, y otro realizado siete años antes. ${ }^{7}$

$\mathrm{Al}$ releer, con ocasión de esta nueva visita, mis propias palabras he revivido y aumentado el sentimiento de admiración, y aún de estupor, que sentí en esas dos ocasiones y en otras ulteriores. El mismo que levanta en todos sus visitantes esta increíble ciudad dedicada a San Pablo, cifra y compendio de la magnífica república brasileña. Testifiqué entonces la "impresionante realidad brasileña", constitutiva de "un continente dentro de otro continente" Me apropié el prognóstico hecho por Stephan Zweig cuando dijo que "Brasil es el país del futuro" y me atreví a ponerle plazo, apostillando que "no hay duda de que Brasil puede llegar a ser la gran potencia del Siglo XXI" Anegado de nuevo mi espíritu en los mismos sentimientos de admiración y de esperanza, vuelvo a apostar para que esas profecías se cumplan para todo el país, para todos sus juristas y, particularmente, para vosotros los claustrales de la Facultad de Derecho paulista.

6. Para componer el sucinto elenco anterior he aprovechado las noticias que dan los ya citados Alfredo Morles (1972), Miguel Reale (1973 Y 1974), Mario G. Losano (1974), Nelson Saldanha (1983) y Sampaio Ferraz (1985 \& 1989). y además, Luis Recaséns Siches en su Panorama del Pensamiento Jurídico en el Siglo XX (México, Porrúa, 1963, p. 548-576), que a pesar de su título comprende también la historia del siglo XIX, o sea la historia enterna del pais. Y Tercio Sampaio Ferraz, en su Introdução ao estudo do direito, São Paulo, Atlas, 1988.

7. En 1951. Ver "El Gran Brasil", en mi libro Sociedad, Política y Gobierno en Hispanoamérica, Madrid, Instituto de Estudios Políticos, 1962, p. 283-324. 
Por lo demás, sólo me resta cumplir con el satisfactorio deber de darlos las gracias por vuestros agasajos y por haberme dado esta ocasión de expresaros mis ideas y sentimientos. ¿Habría bastado con expresar brevemente la gratitud que os debo y acabar ahí mi espuesta a vuestros saludos y ofrecimientos? Creo que no. En todo caso, quod scripsit, scriptum. La cordialidad con que habeis sobrepasado el estricto protocolo me ha incitado a excederme yo también un poco, $\mathrm{y}$ me ha animado a tomarme la libertad de actuar por unos minutos como un Profesor Visitante, no de Curso, ni de Cursillo, sino sólo de Lección y aún, si eso parece excesivo, de leccioncilla, ofreciéndoos una sencilla reflexión sobre el culto al derecho que profesamos todos los aquí reunidos. No sin pecar de osadía, pues ése no es precisamente un asunto de los que se pueden despachar con brevedad y por el procedimiento de urgencia.

Espero y deseo, con todo, que -estando como estamos en una Facultad de Derecho, y siendo casi todos los presentes juristas en ejercicio, o profesores de derecho brasileño, o las dos cosas- hayan podido suscitar algún interés esas reflexiones improvisadas sobre la jurisprudencia y el derecho brasileño que os ha confiado un colega extranjero que, habiendo sido durante muchos años profesor de Derecho Constitucional en la Universidad Complutense de Madrid, ha tenido siempre una insaciable curiosidad por el derecho comparado y en especial por los sistemas jurídicos latinoamericanos. En todo caso, si esas esperanzas y deseos no se han cumplido, pido perdón por haberos distraído mientras, motivado irresistiblemente por el ambiente universitario que aquí se respira, retomaba en voz alta una reflexión iniciada ya hace varios decenios.

Lo que de cierto sí se van a ver cumplidos, estoy seguro, son mis mejores deseos de larga y fructífera vida para la Facultad de Derecho de la Universidad de Sao Paulo y para todos sus claustrales, servidores, alumnos, profesores y mandatarios.

He dicho. 